\title{
LYPD3 Positive
}

National Cancer Institute

\section{Source}

National Cancer Institute. LYPD3 Positive. NCI Thesaurus. Code C132243.

Indicates that LYPD3 expression has been detected in a sample. 